Original Research Paper

\title{
Enrichment Pupuk Organik Asal Kotoran Ternak di CV Gumukmas Multi Farm Jember
}

\author{
Dwi Erwin Kusbianto $^{1}$, Listya Purnamasari², Himmatul Khasanah ${ }^{2}$ \\ ${ }^{1}$ Program Studi Ilmu Pertanian/Perkebunan, Fakultas Pertanian, Universitas Jember, Jember, Indonesia. \\ ${ }^{2}$ Program Studi Peternakan, Fakultas Pertanian, Universitas Jember, Jember, Indonesia.
}

https://doi.org/10.29303/jpmpi.v3i2.1062

Sitasi: Kusbianto, D. E., Purnamasari, L \& Khasanah, H. (2021). Enrichment Pupuk Organik Asal Kotoran Ternak di CV Gumukmas Multi Farm Jember. Jurnal Pengabdian Magister Pendidikan IPA, 4(4)

\section{Article history}

Received: 15 September 2021

Revised: 20 September 2021

Accepted: 30 November 2021

*Corresponding Author: Listya Purnamasari, Universitas Jember, Jember, Indonesia; Email:

listyap.faperta@unej.ac.id

\begin{abstract}
CV Gumukmas Multi Farm as a service partner is one of the entrepreneurs in the sociopreneur-based livestock sector who collaborates with smallholder farmers as partners. The problem faced by partners is the high population of sheep that are kept so that they produce abundant livestock manure but are not used optimally so that they pollute the environment. The solution is structured training and demonstration in the manufacture of nutrient-rich organic fertilizer. Success in the management of manure waste is indicated by the results of compost that resemble soil and do not smell. This service program has improved the skills of farmers in managing livestock manure waste into processed organic fertilizers that can be used in agricultural land/forage for animal feed and improving the environmental conditions of the cages to be cleaner and healthier.
\end{abstract}

Keywords: kotoran ternak, pupuk organik, pengabdian

\section{Pendahuluan}

Populasi domba di Jember terus mengalami peningkatan dari tahun ketahun dan diantaranya berasal dari Kecamatan Gumukmas. Populasi ternak ruminansia pada tahun 2020 adalah sapi potong 8620 sapi potong, 7002 kambing dan 4521 domba (BPS, 2020). CV Gumukmas Multi Farm (GMF) merupakan bisnis yang membawahi atau bermitra dengan para peternak di Gumukmas. Domba banyak diusahakan karena memilki berbagai keunggulan, yaitu mudah beradaptasi terhadap lingkungan dan memiliki daya tahan tubuh yanglebih kuat dibanding ternak jenis lain (Sudarmono \& Sugeng. 2011).

CV GMF dan peternak mitra telah menjalankan proses produksi sesuai good management practices. Namun masih ada kendala yaitu belum optimalnya pengolahan limbah/kotoran ternak. Kotoran ternak selama ini hanya di tumpuk dan dibiarkan saja. Tumpukan kotoran ternak yang dibiarkan akan menjadi sumber penyakit bagi ternak dan dapat mencemari lingkungan yaitu polusi udara. Disisi lain polusi udara juga menimbulkan ketidaknyamanan dan protes dari warga sekitar.

Kotoran ternak yang diproduksi secara konvensional menjadi pupuk kandang dapat memiliki nilai nutrient $2.34 \% \mathrm{~N}, 1.08 \% \mathrm{P}$ dan $0.69 \%$ K (Hartatik dan Widowati, 2020). Peningkatan kualitas pupuk kandang dapat dilakukan dengan pengayaan yang salah satunya dapat dilakukan dengan penambahan PGPR (Plant Growth Promoting Rhizhobacteria) dan Mikroorganisme Lokal (MOL) (Purnamsari et al., 2020), penambahan mikroba elarut fosfat, antara lain Bacillus sp., Pseudomonas sp. dan Streptomyces sp. (Rahayu et al., 2004). penambahan mikoriza, mikroba penambat $\mathrm{N}$ dari udara atau mikroba pemantap agregat tanah: Aeromonas sp. dan Aspergillus sp. (Goenadi, 2004

Tujuan dari kegiatan pengabdian ini yaitu meningkatkan keterampilan peternak CV GMF 
dalam perbaikan lingkungan sekitar dan meningkatkan nilai guna limbah peternakan sehingga dapat diintegrasikan dengan lahan hijauan makanan ternak serta produk olahan limbah dapat dipasarkan dengan baik.

\section{Metode}

Upaya yang dilakukan yaitu untuk mentransfer teknologi dalam optimalisasi limbah kotoran ternak yang belum optimal yaitu (1) sosialisasi dan FGD tentang manajemen pengelolaan limbah kotoran ternak. (2) pelatihan dan percontohan terstruktur dalam pembuatan pupuk organik. Teknologi fermentasi digunakan dalam pengelolaan limbah kotoran ternak dengan pembuatan pupuk penambahan nutrient mineral dan mikroorganisme lokal (MOL) untuk meningkatkan kandungan hara yang dihasilkan (3) Melakukan monitoring dan evaluasi manajemen pengelolaan limbah kotoran ternak.

\section{Metode pengolahan pupuk organik padat}

Proses pembuatan pupuk organik padat diawali dengan melakukan formulasi pupuk dengan penambahan bahan tambahan untuk memperkaya nutrisi yaiu mineral dolomit, pengambilan kotoran ternak dari kandang dan pengumpulan pada terpal/rumah kompos, kotoran yang sudah terkumpul ditambahkan dedak sebagai energi bakteri dan bakteri fermentor yang bisa diperoleh dari Mikroorganisme lokal. Pupuk difermentasi selama 21 hari secara anaerob (tanpa udara).

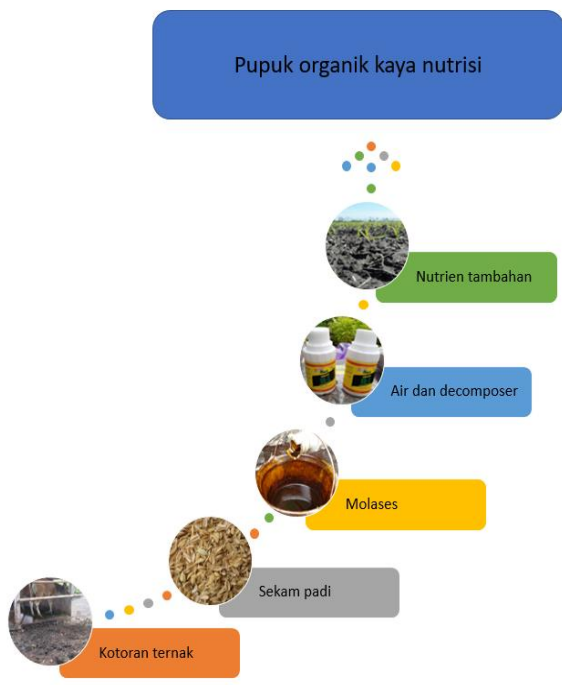

Gambar 1. Flowchart pengolahan pupuk organik

\section{Hasil dan Pembahasan}

Jumlah ternak sapi dan domba yang ada di kemitraan CV GMF sebanyak 20 ekor dan 215 ekor sehingga dihasilkan kotoran ternak segar sebesar $600-800 \mathrm{~kg}$ KTS sapi/hari dan 430Kg KTS domba/ hari. Dalam satu bulan dapat memproduksi 18 ton kotoran sapi dan 12.9 ton kotoran domba.

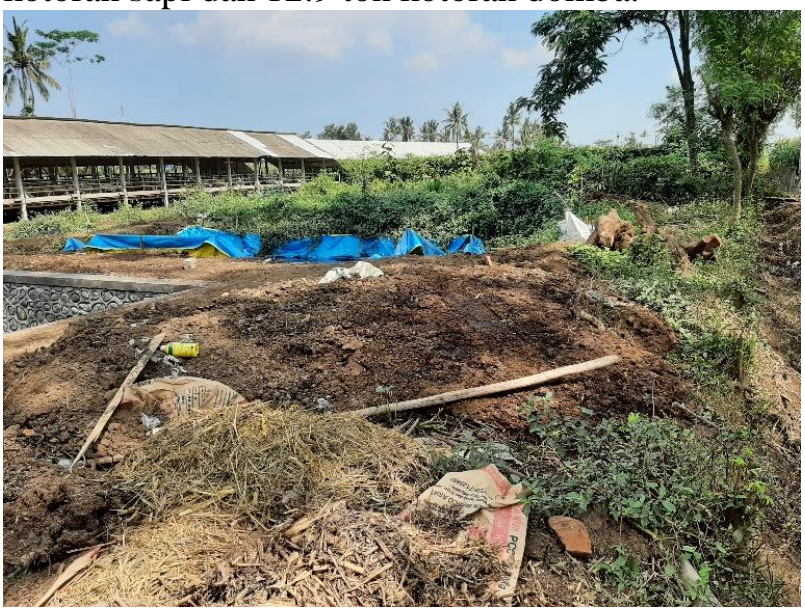

Gambar 2. Potensi limbah di CV. GMF

Potensi biomassa yang di hasilkan oleh ternak sangat bervariasi dan tergantung dengan jenis, pakan serta system pemeliharaan. Hubungan antara bobot ternak dengan jumlah kotoran (feses) yang diproduksi disajikan pada Tabel 1. CV Gumukmas Multi Farm memproduksi sapi potong dan domba, sehingga sumber kotoran ternak dapat diperoleh dari dua jenis ternak tersebut.

Tabel 1. Hubungan antara Bobot Ternak dengan Kotoran yang Dihasilkan

\begin{tabular}{|l|l|l|l|}
\hline \multicolumn{1}{|c|}{$\begin{array}{l}\text { Jenis } \\
\text { Ternak }\end{array}$} & \multicolumn{1}{|c|}{$\begin{array}{c}\text { Bobot } \\
\text { Sapi/ekor }\end{array}$} & $\begin{array}{c}\text { Produksi } \\
\text { kotoran } \\
\text { ternak } \\
\text { kg/hari) }\end{array}$ & $\begin{array}{c}\text { \%bahan } \\
\text { kering }\end{array}$ \\
\hline $\begin{array}{l}\text { Sapi } \\
\text { Potong }\end{array}$ & $\mathbf{5 2 0}$ & $\mathbf{2 9}$ & $\mathbf{1 2}$ \\
\hline Sapi Perah & 640 & 50 & 14 \\
\hline $\begin{array}{l}\text { Ayam } \\
\text { petelur }\end{array}$ & 2 & 0,1 & 26 \\
\hline $\begin{array}{l}\text { Ayam } \\
\text { Pedaging }\end{array}$ & 1 & 0,06 & 25 \\
\hline Babi & 90 & 7 & 9 \\
\hline Domba & $\mathbf{4 0}$ & $\mathbf{2}$ & $\mathbf{2 6}$ \\
\hline \multicolumn{2}{|l|}{ Aliran nutrisi tersebut erat kaitannya }
\end{tabular}

dengan dampak peternakan terhadap lingkungan baik terhadap polusi tanah, udara dan air. Pengolahan limbah kotoran ternak perlu dilakukan untuk mengurangi dampak pencemaran lingkungan 
baik tanah, udara maupun air. Perbaikan lingkungan dari adanya polusi yang berasal dari peternakan salah satunya dilakukan dengan pembuatan pupuk organik. Kurang lengkapnya kandungan pupuk organik dapat ditingkatkan dengan melakukan pengkayaan/enrichment dengan bahan lain.

\section{sosialisai tentang manajemen pengelolaan limbah kotoran ternak}

Kegiatan pengabdian ini diawali dengan sosialisasi dan FGD untuk persiapan pelaksanaan keseluruhan program. Pada kegiatan sosialisasi program ini, dipaparkan tujuan dan kegiatan yang akan dilakukan selama program pengabdian (Gambar 3). Dalam mengatasi masalah dari melimpahnya limbah kotoran ternak maka program yang dilaksanakan yaitu pengolahan kompos.

Kompos yang baik adalah yang sudah cukup mengalami pelapukan dan dicirikan oleh warna yang sudah berbeda dengan warna bahan pembentuknya, tidak berbau, kadar air rendah dan sesuai suhu ruang. Kecepatan suatu bahan menjadi kompos dipengaruhi oleh kandungan $\mathrm{C} / \mathrm{N}$ semakin mendekati $\mathrm{C} / \mathrm{N}$ tanah maka bahan tersebut akan semakin lebih cepat menjadi kompos (Simamora dan Salundik, 2006). Proses pembuatan dan pemanfaatan kompos dirasa masih perlu ditingkatkan agar dapat dimanfaatkan secara lebih efektif, menambah pendapatan peternak dan mengatasi pencemaran lingkungan.

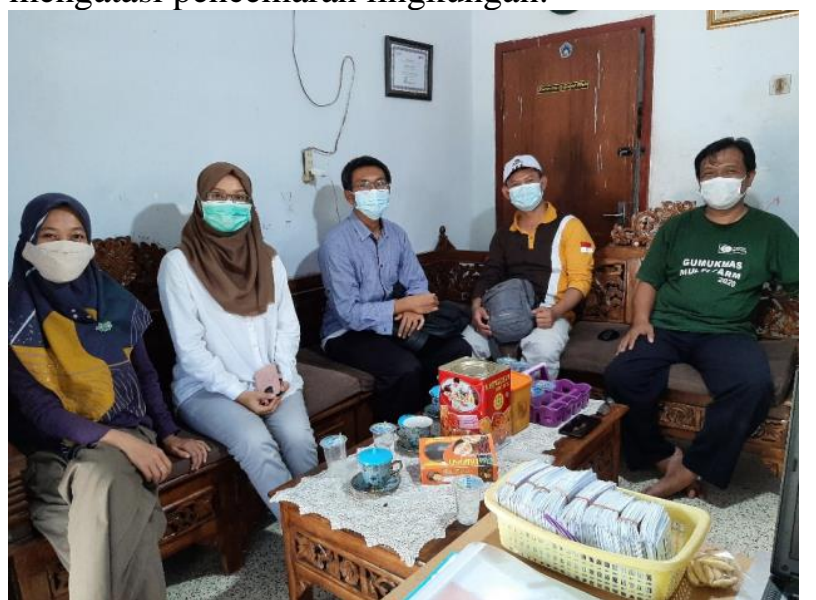

Gambar 3. Sosialisasi kegiatan dengan mitra CV. GMF

\section{Pelatihan pengolahan pupuk organik padat}

Adapun kandungan nutrient limbah pertanian disajikan pada tabel 2

Tabel 2 Kandungan nutrisi limbah pertanian
(\%)

\begin{tabular}{|l|l|l|l|l|}
\hline $\begin{array}{l}\text { Limbah } \\
\text { pertanian }\end{array}$ & $\begin{array}{l}\text { Bahan } \\
\text { organik }\end{array}$ & Nitrogen & fosfor & Pottasium \\
\hline $\begin{array}{l}\text { Kotoran } \\
\text { sapi }\end{array}$ & 30.34 & 1.5 & 0.96 & 1.23 \\
\hline $\begin{array}{l}\text { Kotoran } \\
\text { ayam }\end{array}$ & 34.38 & 2.87 & 1.56 & 1.68 \\
\hline $\begin{array}{l}\text { Limbah } \\
\text { batang } \\
\text { jagung }\end{array}$ & 58.9 & 0.72 & 0.25 & 1.5 \\
\hline
\end{tabular}

Sumber: (Huang et al., 2018)

Teknologi fermentasi digunakan dalam pengelolaan limbah kotoran ternak menjadi pembuatan pupuk organik dengan penambahan nutrient dolomit dan pemanfaatan mikroorganisme lokal untuk meningkatkan kandungan hara yang dihasilkan (Gambar 4 dan 5). Penggunaan mikroorganisme lokal bertujuan sebagai starter dalam pengolahan pupuk organik (Khasanah, et al. 2020). Prinsip pengolahan pupuk organik ini adalah penggunaan aktivitas mikroba untuk mempercepat penguraian bahan-bahan organik (Purnamasari, et al. 2020).

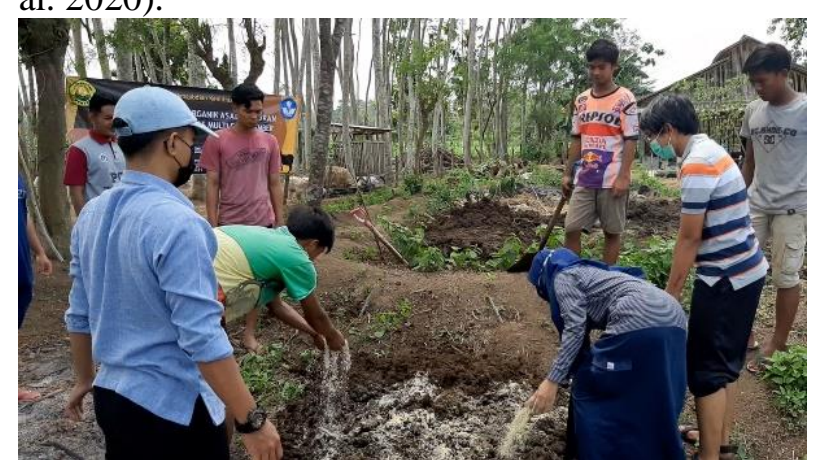

Gambar 4. Proses pengolahan kotoran ternak menjadi pupuk organik

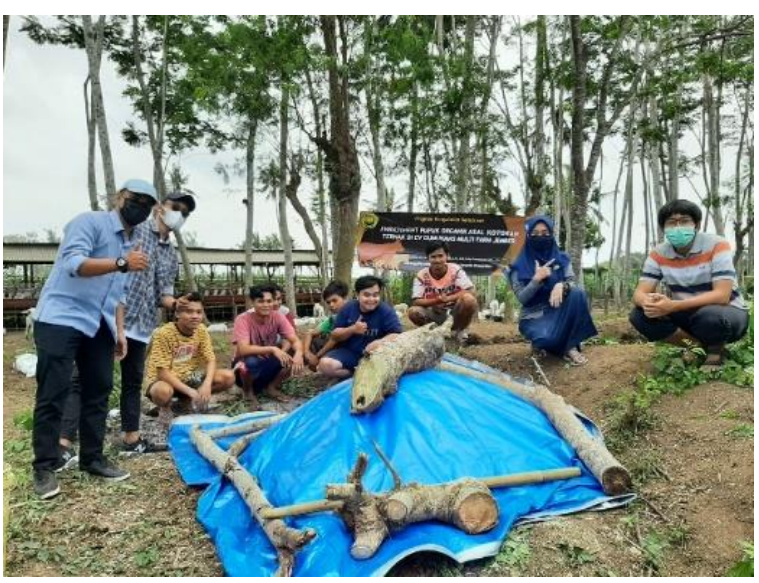

Gambar 5. Proses pengomposan 


\section{Kesimpulan}

Kesimpulan dari program pengabdian yang telah dilakukan yaitu:

1. Pelatihan dan penyuluhan mengenai pengolahan limbah ternak menjadi pupuk organik kaya nutrisi telah diikuti oleh peternak CV. Gumukmas Multi Farm dengan antusias.

2. Peningkatan nilai nutrient pupuk organik dilakukan dengan penambahan mineral dolomit dan menggunakan mikroorganisme lokal.

3. Optimalisasi pengolahan limbah kotoran ternak diharapkan dapat mengurangi dampak pencemaran lingkungan dan memberikan nilai tambah pada limbah yang masih kurang termanfaatkan.

\section{Saran}

Kegiatan pengabdian ini harus dilanjutkan sampai ke tahap komersialisasi produk pupuk organik yang telah dilakukan. Inovasi dan kreativitas dalam pengemasan produk dapat dilakukan untuk meningkatkan nilai jual pupuk organic. Lebih lanjut legalisasi produk juga penting yaitu dengan mendaftarkan izin edar maupun merk dagangnya.

\section{Ucapan Terima Kasih}

Ucapan terima kasih disampaikan kepada LP2M Universitas Jember melalui hibah program pengabdian kemitraan tahun anggaran 2021. Fakultas Pertanian Universitas Jember yang telah memberikan dukungan baik moral maupun material. CV. Gumukmas Multi Farm sebagai mitra dalam program ini

\section{Daftar Pustaka}

Badan Pusat Statistik. 2020. Kecamatan Gumukmas dalam Angka. Badan Pusat Statistik Kabupaten Jember,

Goenadi, D. H., 2004, Teknologi Konsumsi Pupuk yang Minimal, Kompas, 15 Mei 2004.

Hartatik, W dan Widowati, L.R. 2020. Pupuk Kandang.

https://balittanah.litbang.pertanian.go.id/ind /dokumentasi/lainnya/04pupuk\%20kandang .pdf

Huang, D.D., Cao, G.J., Geng, Wang, L.C., Chen, \& Liang. 2018. Impact of Agricultural Waste
Return on Soil Greenhouse Gas EmissionS. https://doi.org/10.15666/aeer/1701_1321133 5

Khasanah, H., Purnamasari, L. and Kusbianto, D.E., 2020, January. Pemanfaatan MOL (Mikroorganisme Lokal) sebagai Substitusi Biostarter EM4 untuk Meningkatkan Kualitas Nutrisi Pakan Fermentasi Berbasis Tongkol dan Tumpi Jagung. In Prosiding Seminar Nasional Teknologi Peternakan dan Veteriner : 357-364.

Purnamasari, L. Purnomo, H. dan Setyawan, H.B. 2020. Exploration of local microorganisms from rumen and their potential to make silage from agricultural waste. ASEAN Journal on Science \& Technology for Development. 37 (3): 109 - 114. DOI 10.29037/ajstd.642

Purnamasari, L., Krismaputri, M.E., Khasanah, H. \& Widodo, N. 2020. Peningkatan Kemandirian Peternak Desa Klabang Melalui Village Breeeding Center dan Penerapan Teknologi Pengolahan Pakan Lokal. Jurnal SEMAR Vol. 9 No. 2, hal. 15 -24 .

Rahayu, S. P., Noer, S. T. H., Rahmi, D., Agustina, S. Dan Widianto, T., 2004, Peningkatan Mutu Pupuk Organik dengan Penambahan Unsur Kalium dari Limbah Industri Kelapa Sawit dan Unsur Fosfor dari Batuan Fosfat, Bul. Penel., 26, 28-35.

Simamora, S. dan Salundik. 2006. Meningkatkan Kualitas Kompos. AgroMedia Pustaka. Jakarta.

Sudarmono, A.S dan Sugeng, Y.B. 2011. Beternak Domba. Penebar Swadaya. Jakarta 